\title{
MENGENALI KARAKTERISTIK KONTROL ON-OFF DENGAN GRAFIK LOGIKA
}

\author{
Burhan Liputo $^{1)}$, Iqrima Staddal ${ }^{1)}$, Arif Murtaqi Akhmad Mutsyahidan ${ }^{2)}$ \\ 1) Program Studi Mesin dan Peralatan Pertanian, Politeknik Gorontalo \\ 2) Program Studi Teknologi Hasil Pertanian, Politeknik Gorontalo \\ Email: burhanliputo@poligon.ac.id ${ }^{1)}$
}

\begin{abstract}
ABSTRAK
Salah satu metode sederhana untuk menjelaskan prinsip kerja kontrol adalah dengan menggunakan metode grafik logika atau istilah grafik logika kontrol. Grafik logika adalah teknik yang dapat menunjukkan prinsip kerja rangkaian kontrol dalam bentuk logika 0 (nol) dan logika 1 (satu) atau dalam bentuk notasi lain seperti Low (L) dan High (H). Grafik logika bisa menjadi acuan untuk menguji cara kerja pengontrolan, atau sebagai penerjemah prinsip kerja rangkaian kontrol dalam bentuk diagram grafik. Makalah ini adalah bagian dari hasil penelitian tentang media eksperimen kontrol dengan fokus bahasan adalah grafik logika kontrol yang menggunakan relay magnetik tipe LY2NJ dan komponen mekanis lainnya. Tujuannya adalah untuk mengenali secara detail prinsip kerja rangkaian kontrol ON-OFF dan cara kerja komponen-komponen yang digunakan. Metode yang digunakan untuk mendapatkan informasi kontrol ON-OFF dan cara kerja komponen yang digunakan adalah deskripsi algoritma, konstruksi rangkaian dan grafik logika.
\end{abstract}

Kata kunci: Logika, Grafik, Kontrol, Relay LY2NJ.

\section{ABSTRACT}

A straight forward method to explain the working principle of control is the logic graph method or another term that is control logic. Control logic graph is a technique that can show the working principle of a control circuit in the form of logic 0 (zero) and logic 1 (one) or in the form of other notations such as Low (L) and High (H). Logic graphs can be a reference to test how the control works, or as a translator of the working principle of a control circuit in the form of a graph diagram. This paper is part of the results of research on experimental control media, with the focus of discussion is the logic graph of control using LY2NJ type magnetic relays and other mechanical components. The aim is to identify in detail the working principle of the ON-OFF control circuit and the workings of the ingredients used. The method used to get ON-OFF control information and how the components work are algorithm descriptions, circuit construction, and logic graphs.

Keywords: Logic, Graph, Control, LY2NJ Relay.

\section{PENDAHULUAN}

Trainer kontrol adalah media eksperimen laboratorium yang digunakan untuk pembelajaran dasar kontrol yang merupakan gabungan antara model kerja dan mock-up. Trainer ditujukan untuk menunjang proses pembelajaran peserta didik dalam menerapkan pengetahuan/konsep yang diperolehnya pada benda nyata, obyek yang sesungguhnya atau benda model yang mirip sekali dengan benda nyatanya (Marpanaji, 2017). Proses pembelajaran sendiri terdapat beberapa faktor yang dapat mempengaruhi kegiatan proses sistem pembelajaran, salah satu diantaranya adalah media pembelajaran yang menunjang. Media adalah satu solusi untuk membuat pembelajaran lebih baik dan dapat menarik peserta didik untuk lebih antusis dalam mengikuti pembelajaran (Sarwano, 2018). Media pembelajaran yang dikembangkan untuk menjelaskan konsep struktur sistem, mempunyai tahapan yaitu berupa simbol-simbol verbal yang digambar/ditulis langsung pada papan tulis dengan menarik garis penghubung antar saluran secara manual, menampilkan model terbuat dari bahan plastik, dan media pembelajaran yang menggunakan sistem komputer (Purnawan, 2012). Salah satu manfaat media trainer kontrol adalah dapat menjelaskan prinip kerja rangkaian, sebagai contoh rangkaian kontrol DOL berikut ini :

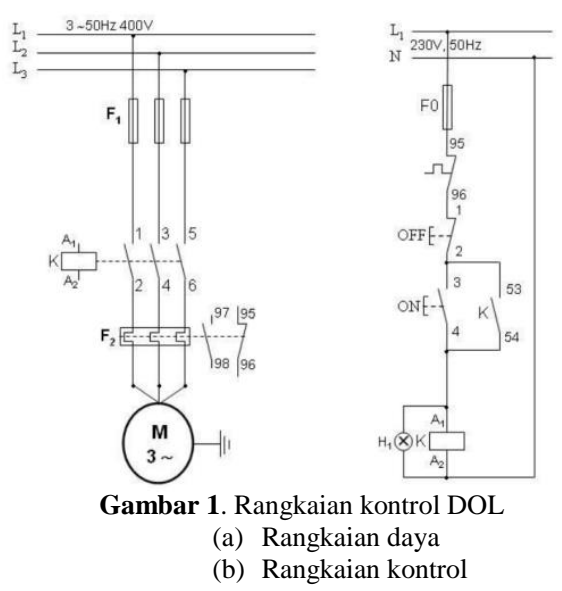

Pengontrolan motor dengan DOL (direct on line) adalah jika tombol ON ditekan, kontaktor $\mathrm{K}$ akan 
bekerja, lampu H1 akan menyala dan motor akan bekerja. Jika tombol ON dilepas, maka rangkaian kontrol akan tetap bekerja (run). Kondisi ini disebabkan oleh fungsi Tombol ON diambil alih oleh kontak NO nomor 53-54 kontaktor K sehingga kontak saklar terkunci (Putra, 2016). Berbagai macam model media pembelajaran merupakan pengembangan untuk memberikan hasil pembelajaran praktikum kontrol akan lebih baik dan lebih efektif serta mudah dipahami. Sebagai langkah awal sebelum proses pengujian rangkaian pada media trainer dilaksanakan adalah langkah pengenalan fungsi rangkaian dan mengetahui secara detail dan sistematis cara kerja komponen yang digunakan dalam rangkaian kontrol. Langkahlangkah dimaksud adalah pembuatan deskripsi algoritma, perancangan rangkaian kontrol, dan pembuatan grafik logika kontrol. Tujuan metode ini adalah untuk memastikan bahwa sistem rangkaian

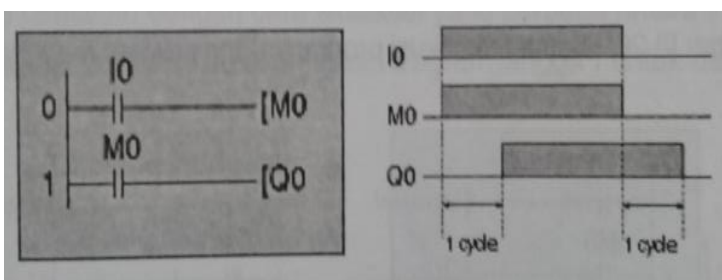

kontrol yang akan diuji sudah sesuai dengan fungsi rancangan yang dibangun. Salah satu penerapan metode ini adalah pada rangkaian kontrol ON-OFF yang menggunakan komponen relay magnetik dan komponen mekanis penunjang. Diantara penggunaan grafik logika adalah kontrol PLC (Programmable Logic Controller). Sebagai contoh, status ON/OFF yang dihasilkan oleh kontak keluaran tidak dapat digunakan sebagai status kontak masukan dalam siklus yang sama, perhatikan contoh yang ditunjukkan pada Gambar 3. Saat I0 menjadi ON, maka M0 digaris 1 masih dalam kondisi OFF sehingga efeknya Q0 akan ON untuk siklus berikutnya, demikian juga saat I0 menjadi OFF (Putra E.A: 2004).

Gambar 1. Grafik logika kontrol ON-OFF unlock

\section{METODE PELAKSANAAN}

Ada tiga langkah sederhana untuk mengenali prinsip kerja rangkaian kontrol yang menggunakan komponen relay magnetik dan komponen mekanis yaitu deskripsi algoritma, konstruksi kontrol, dan grafik logika. Langkah-langkah ini dapat menjadi metode sederhana untuk mengenali prinsip dan karakteristik kerja dari rangkaian kontrol yang menggunakan komponen relay magnetik dan komponen mekanis. Berikut adalah diagram alir pengenalan prinsip kerja kontrol ON-OFF menggunakan relay magnetik LY2NJ dengan menggunakan motor listrik satu fasa sebagai beban

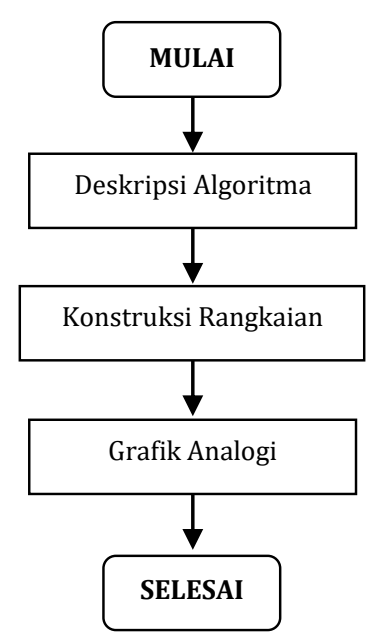

Gambar 2. Diagram alir rancangan grafik

\subsection{Deskripsi Algoritma}

Prinsip kerja kontrol rangkaian ON-OFF dapat dijabarkan secara detail dalam bentuk deskripsi algoritma yang memproyeksikan karakteristik kerja dari tiap-tiap komponen yang bekerja dalam rangkaian kontrol. Prinsip deskripsi algoritma kontrol ON-OFF dalam konteks penelitian ini hanya menggunakan komponen relay magnetik dan beberapa komponen mekanik penghubung. Struktur algoritma ini terdiri dari instruksi input, proses dan output. Instruksi input yaitu menghubungkan komponen pengaman pemutus rangkaian CB (Circuit Breaker), Instruksi proses yaitu mengoperasikan tombol ON-OFF, dan instruksi output yaitu relay magnetik dan indikator kerja. Berikut adalah deskripsi algoritma kontrol ON-OFF menggunakan relay magnetik :

Tabel 1. Algoritma kontrol ON-OFF :

\begin{tabular}{ll}
\hline \multicolumn{1}{c}{ Instruksi } & \multicolumn{1}{c}{ Keterangan } \\
\hline Input & Menghubungkan pengaman CB \\
Proses & Mengoperasikan tombol ON-OFF \\
Output & Relay bekerja (running), \\
& Indikator menyala \\
\hline
\end{tabular}

\subsection{Konstruksi Rangkaian}

Konstruksi rangkaian kontrol ON-OFF dapat dirancang berdasarkan deskripsi algoritma dengan mengikuti tahapan instruksi kerja secara urutan kerja dalam deskripsi. Rangkaian kontrol ON-OFF akan terbentuk dan membentuk fungsi yang sesuai dengan instruksi dalam keterangan algoritma. Setelah dibentuk menjadi konstruksi rangkaian kontrol maka fungsi-fungsi komponen dapat ditransformasikan lagi dalam bentuk diagram grafik logika untuk memastikan kembali bahwa deskripsi algoritma telah sesuai dengan konstruksi rangkaian kontrol yang dibangun.

\subsection{Grafik Logika}

Membuat grafik logika suatu prinsip kerja kontrol ON-OFF yang sudah melalui tahapan 
deskripsi algoritama dan perancangan konstruksi rangkaian, secara spesifik harus memperhatikan urutan garis penghubung atau saluran penghantar dan urutan komponen yang digunakan. Hal ini dimaksudkan untuk tindakan penyesuaian dan penempatan keadaan komponen pada diagram grafik logika. Grafik logika akan memberikan penjelasan secara sederhana karakteristik fungsi komponen dengan memberikan asumsi pada kondisi normal dan dioperasikan dalam bentuk sinyal kotak berupa logika 1 (satu) atau logika 0 (nol). Logika ini dapat didefinisikan dengan keadaan aktif/kerja dan tidak aktif/tidak kerja.

\section{HASIL DAN PEMBAHASAN}

Makalah ini akan membahas tentang salah satu bahasan hasil penelitian media eksperimen yaitu mengenai grafik logika kontrol yang dibangun berdasarkan deskripsi algoritma dan konstruksi rangkaian sehingga akan menjelaskan prinsip kerja kontrol dan komponen yang digunakan.

\subsection{Kontrol ON-OFF Unlock (Tanpa Pengunci)}

Langkah bagi pemula untuk memahami aplikasi kontrol sederhana adalah dengan melakukan percobaan dan pengamatan langsung prinsip kerja rangkaian kontrol dasar ON-OFF (swicthing). Alasan ini dimaksudkan karena kontrol dasar ON-OFF dapat menggambarkan prinsip kerja mekanik yang dapat diamati langsung secara konstruktif baik pada komponen aktif ataupun komponen pasif. Berikut adalah rangakaian kontrol dasar ON-OFF (switching) menggunakan komponen aktif relay dan komponen pasif tombol tekan :
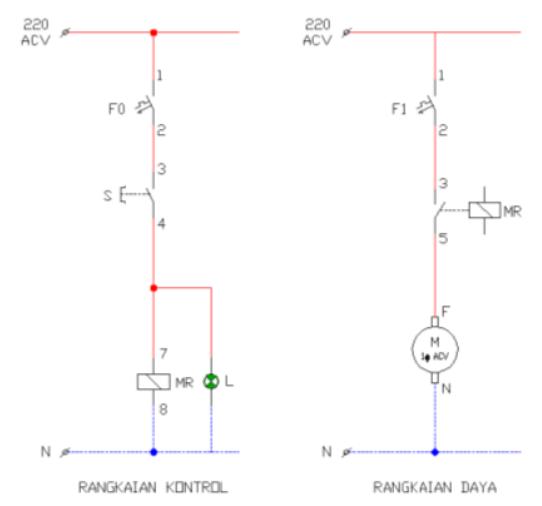

Gambar 3. Rangkaian kontrol ON-OFF unlock dan rangkaian daya

Skema rangkaian Gambar 3 terdiri dari komponen pemutus rangkaian atau fuse (F0, F1), tombol OnOff $(\mathrm{S})$, relay magnetik (MR), lampu indikator (L) dan motor listrik satu fasa (M). Fungsi F0 dan F1 adalah sebagai pengaman untuk memutus daya, tombol S sebagai operator $\mathrm{ON}-\mathrm{OFF}$, relay $\mathrm{MR}$ sebagai saklar otomatis (auto switch), dan lampu indikator L sebagai tanda rangakaian kontrol aktif mengendalikan motor sebagai beban yang dikendalikan. Prinsip kerja kontrol ON-OFF tanpa engunci (unlock) dapat dijelaskan dengan menggunakan grafik logika berikut :

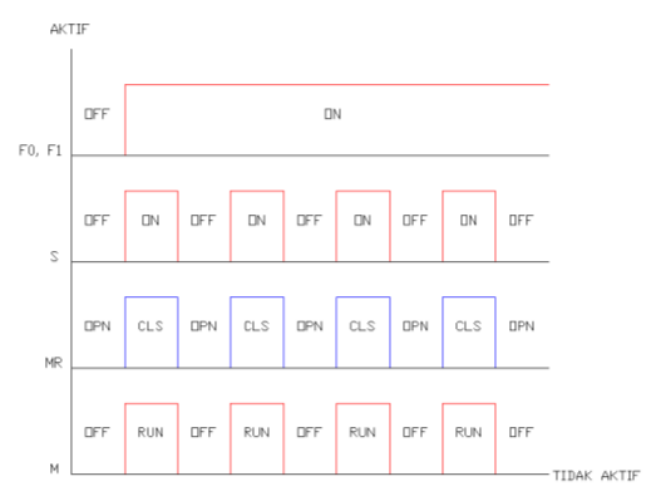

Gambar 4. Grafik logika kontrol ON-OFF unlock

Grafik logika kontrol ON-OFF unlock bekerja mengendalikan motor listrik satu fasa melalui kontak MR (relay magnetik) sebagai fungsi transfer switch. Grafik ini menjelaskan bahwa jika rangkaian kontrol dalam keadaan normal, maka semua komponen dalam kondisi tidak aktif (OFF) atau sistem kontrol tidak difungsikan. Jika tombol saklar (S) ditekan dalam waktu tertentu, maka relay MR bekerja (ON) dan kontak MR (3-5) akan menutup bersamaaan indikator lampu L menyala. Jika kondisi MR bekerja maka motor listrik MR akan bekerja (ON) karena telah mendapat sumber daya listrik melalui hubungan kontak MR (transfer swicth) pada relay. Jika tombol saklar S dilepas (tak ditekan) maka relay MR, lampu $\mathrm{L}$ dan motor $\mathrm{M}$ akan kembali normal atau tidak bekerja (OFF), dan begitu seterunsya.

\subsection{Kontrol ON-OFF On Lock}

Secara prinsip, rangkaian kontrol ON-OFF On Lock hampir memiliki kesamaan pada prinsip kerja dengan rangkaian kontrol ON-OFF Unlock. Perbedaannya hanya terdapat kontak pengunci pada kontrol on lock. Berikut rangkaian kontrol ON-OFF dengan sistem pengunci (On Lock) dan rangkaian daya :
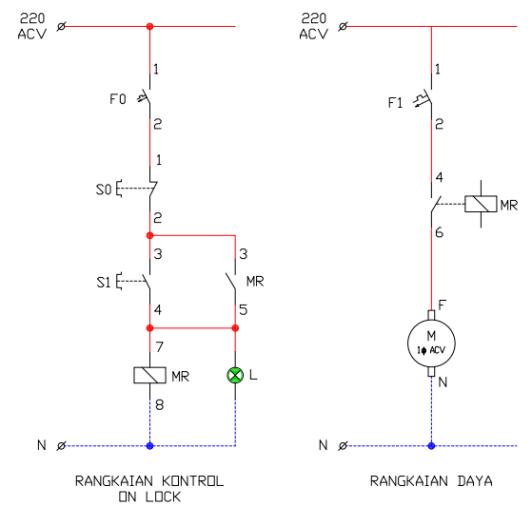

Gambar 5. Rangkaian kontrol ON-OFF on lock dan rangkaian daya 
Prinsip kerja rangkaian kontrol ON-OFF On Lock adalah : dalam keadaan F0 dan F1 terhubung, apabila tombol $\mathrm{S}$ ditekan sesaat, maka relay $\mathrm{MR}$ bekerja, kontak MR (3-5) dan kontak MR (4-6) menutup, lampu indikator L menyala, dan motor $\mathrm{M}$ bekerja. Setelah saklar S1 dilepas (tak ditekan), maka rangkaian kontrol akan tetap bekerja (aktif), motor tetap jalan karena kontak MR (3-5) masih dalam keadaan terhubung dan mengambil alih peran saklar S1 untuk menghubungkan kumparan relay MR pada sumber daya listrik. Jika saklar S0 ditekan, maka relay MR dan semua kontak MR akan normal kembali (membuka), dan motor $\mathrm{M}$ akan OFF (tidak bekerja). Prinsip kerja kontrol ON-OF On Lock dapat diamati pada grafik logika berikut ini :

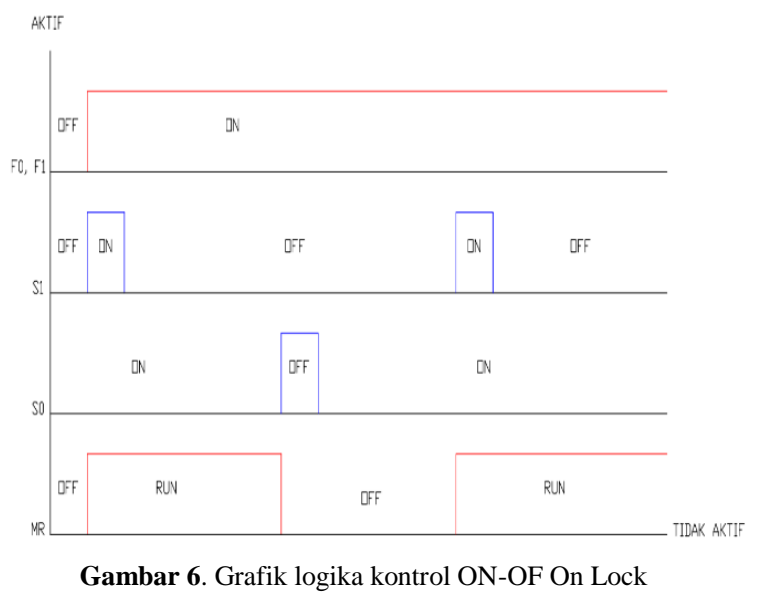

Gambar 8 menjelaskan bahwa relay MR akan bekerja secara kontinyu jika tombol S1 di tekan sesaat. Kondisi ini menyebabkan kontak NO pada realay MR akan menghubungkan belitan relay MR pada sumber tegangan sehingga menyebabkan relay MR tetap dalam keadaan bekerja meskipun tombol S1 telah dilepas (OFF). Jika tombol S0 ditekan sesaat maka relai MR akan OFF (tidak bekerja) dan kontak NO akan terbuka. Skema rangkaian pada Gambar 5, secara konsep dirancang terpisah untuk memudahkan dalam mengidentifikasi masingmading skema. Rangkaian daya akan aktif apabila rangkaian kontrol bekerja dimana kontak MR (relay magnetik) sebagai fungsi transfer switch untuk menghubungkan komponen beban $\mathrm{M}$ (motor) ke sumber daya listrik. Kontak NO akan menutup dan membuka berdasarkan perintah kontrol pada komponen relay magnetik MR.

\section{KESIMPULAN DAN SARAN}

\subsection{Kesimpulan}

Grafik logika kontrol pada prinsipnya adalah metode yang dapat menjelaskan prinsip kerja rangkaian kontrol dan rangkaian daya dalam bentuk grafik gelombang kotak dengan notasi 1 (satu) dan 0 (nol) yang mengartikan keadaan aktif dan tidak aktif. Keadaan logika ini merupakan interpretasi kerja dari komponen kontrol yang digunakan dalam rangkaian sistem.

\subsection{Saran}

Grafik logika kontrol yang diterapkan pada rangkaian kontrol ON-OFF dapat juga digunakan untuk berbagai rangkaian kontrol dari yang sifatnya sederhana ataupun yang sifatnya sangat kompleks. Alasannya adalah bahwa keadaan kerja semua komponen baik pada rangkaian kontrol dan rangkaian daya dapat diinformasikan dalam bentuk grafik logika.

\section{DAFTAR PUSTAKA}

Iqbal, R. (2015). Pengaturan Kecepatan Motor Induksi 3 Fasa Menggunakan Metode Vektor Kontrol Berbasis Jaringan Saraf Tiruan Radial Basis Function - PD (JST RBF - PD) Hybrid. Institut Teknologi Sepuluh Nopember, Teknik Elektro. Surabaya Jawa Timur: Institut Teknologi Sepuluh Nopember.

Ir. Yusuf Ismail Nakhoda, M. (2009). Sistem Kontrol Level Ketinggian Air Pada Tandon Menggunakan SMS Berbasis Smart Relay. SENTIA. Malang: Politeknik Negeri Malang.

Nelwan, P. A. (2003). Teknik Pemrograman dan Antarmuka Mikrokontroler AT89C51. Jakarta: Elex Media Komputindo.

Pioh, J. E. (2016). Pengendalian Motor Listrik dari Jarak Jauh dengan Menggunakan Software Zelio Soft-2 dan Wifi. E-Journal Teknik Elektro dan Komputer, 5 Nomor 2.

Prawiroredjo, K. (2010). Pengatur Ketinggian Air Otomatis. JETri, 9 Nomor 2, 24-44. 